\title{
Foreign language teaching and learning: Challenges and opportunities at Makerere University
}

\author{
William Wagaba \\ Institute of Languages, Makerere University, P.O. Box 7062, Kampala, Uganda \\ E-mail: wwags@arts.mak.ac.ug
}

\begin{abstract}
At Makerere University, foreign language courses in French, German and Arabic are attended by a variety of students at beginner, advanced and voluntary levels. Language students either learn foreign languages as service courses within the framework of academic programmes such as Tourism and Secretarial Studies, or as fully-fledged subjects at undergraduate level. In spite of the emphasis on language skills in job advertisements in the Ugandan press, the teaching of foreign languages tends to be oriented more towards theoretical requirements of academic (language) programmes and numbers of students, rather than toward the intensity of language contact, quality of language courses and students as well as standardised language course evaluations. The criteria for the selection of potential language students and the language learning policy are problematic and partly the cause of the unpopularity of language courses. On the basis of the evaluation of the course "German for Secretarial Studies", the current paper outlines challenges of teaching and learning German as a foreign language. There seems to be a discrepancy between the language skills that job markets require from university graduates and the skills which graduates are likely, at present, to acquire upon completion of their foreign language courses. The paper also focuses on factors that constitute barriers to foreign language learning and recommends ways in which foreign language students and teachers can exploit the potential of the budding Ugandan language industry.
\end{abstract}

Keywords: Foreign language teaching and learning, Ugandan language industry, employability skills, intercultural communication competence, challenges of multilingualism

\section{Introduction}

A quick look at a random sample of job advertisements in the Ugandan weekly newspapers New Vision and Monitor indicates that employers, both in the formal and informal sectors, expect university graduates to have acquired specific qualifications, competences and skills. These skills include excellent written and verbal communication skills, such as the ability to present, train and coach others, speak and write effectively and compellingly, to resolve communication problems and to be proficient in a foreign language.

The following four questions arise in connection with the promotion of teaching foreign languages at university level in the Ugandan context. Firstly, how do considerations regarding funding influence the position of foreign language promotion in an academic environment? 
This question is especially relevant in settings where systematic learning of foreign languages is often considered to be less of a priority than, for example, science subjects. Secondly, how should foreign language teachers, in their role(s) as transmitters of culture, facilitate the link between teaching language skills and enabling students to apply the acquired skills in practical real-life situations after the completion of language courses? Thirdly, what benefits are there to learning a foreign language? And lastly, what role can the promotion of foreign languages play in equipping language students with the employability skills they need to compete in the job market in Uganda today? The present paper will attempt to address these general questions, paying particular attention to the teaching of German as a foreign language at Makerere University.

German has been taught as a foreign language at Makerere University for over 40 years. However, recent figures reveal a decrease in the numbers of language students and, at the same time, a decrease in the demand for language courses at the university. This presents educators with the challenge of justifying the viability of such language courses and programmes. However, foreign language learning and teaching is a domain which is influenced by job market dynamics and an area of specialization in which hardly any documentation and research has been undertaken from the perspective of Ugandan scholars. At Makerere University, promotion of the teaching and learning of foreign languages is a response to the need of the community in a developing country like Uganda, to train and empower different categories of students to communicate with ease and access information and knowledge in today"s skills-oriented global economy. The demonstration of languagerelated employability skills is crucial in at least the domains of business, tourism, hotel management and catering, the hospitality industry and international relations.

As the global marketplace and language service industries rapidly expand, there is a growing demand and need in multicultural working environments and in different areas of specialisation, for effective communicators who are proficient in foreign languages. In other words, it is essential for the global economy to have culturally sensitive stakeholders who are mindful of the fact that subtle communication breakdowns can distort one"s message to potential employers and, also, that differences in cultural values and customs influence business practices both in local and global contexts.

As the content of newspaper advertisements in Uganda indicates, the demand for effective communicators in Uganda is partly in response to the skills-driven job market the world over. It can be argued that language, like any other commodity, can be bought and sold. When treated like an investment, language is a potential asset whose outcome can be compared with other outcomes in a business venture. When treated as a consumer good, the decision to buy (a language) will depend on whether the benefits reaped from buying (that particular language) - whether for purposes of pleasure or tourism, promotion or additional qualification, among others - outweigh the costs in terms of tuition expenses, study materials, and time invested and whether the expectations of the foreign language learner are satisfied.

\section{The foreign language cluster at Makerere University}

According to a 2009 unpublished report presented by the director of the Institute of Languages during a one-day workshop for academic members of staff, a total of 64 teaching staff are currently employed at the Institute. The courses offered include English Language 
Studies, Linguistics, Communication Skills, Secretarial Studies, Social Anthropology, Ugandan languages (referred to as local languages) and foreign languages. A total of 3757 students are currently registered at the Institute, out of which 301 (accounting for $8 \%$ of the students) learn different languages at both advanced and beginner levels. The Foreign Language Cluster consists of Arabic, English as a Foreign Language, French and German. The common areas in this cluster include translation and interpretation, editorial work, classroom and language research, teaching language and culture and developing teaching materials.

The selection criteria and policy for students of languages like Arabic, German and French are problematic in that the choice of the students as to which foreign language they want to learn, is not given priority. The current language learning policy at Makerere University is that priority is given to the decision of the university authorities to allocate the study of languages to students according to their performance at the Advanced Level (A-level) of Secondary Education, as well as the subject combinations students applied for before admission to the university. In principle, students do not choose a language they wish to learn: instead the policy is that students learn the particular language that is selected on their behalf during their first year of study. This policy applies to students who begin learning a foreign language at university level. The current practice is that these students study a total of three subjects during their first year, and have the option of dropping one subject and continuing with only two subjects during the second and third year of their university education. The selection for students of German at advanced level is also based on their A-level results and the subject combination for which they applied. The difference between these groups is that, in the case of the advanced students, the choice, interest in and attitude towards learning a specific foreign language also tends to be reflected in their overall performance and nature of participation in the offered language programmes and courses. This is probably because the students who learn a foreign language at an advanced level have themselves chosen to study the particular language in the past, and now again at university level.

The ideal situation for both language students at beginner and advanced levels would be to target students who are interested in, and motivated to learn a foreign language for a specific purpose, rather than learning the language as an imposed subject. This issue will be discussed in more detail with regard to the German for Secretarial Studies course in Section 4.1.

Judging by records of language students since 1999, there has been a significant decline in the number of students who study a foreign language at undergraduate level at the Institute of Languages at Makerere University. It is likely that this trend characterises students who learn a foreign language for general purposes rather than for a specific purpose. The prevalent attitude among such students towards learning French or German, for example, is that learning a foreign language is like learning any other subject and that they should learn the language in order to get good grades and not as a medium through which information on culture and current political and social issues can be transmitted, managed and processed for specific purposes.

The learning of foreign languages involves the learning of several components, such as language proficiency, communicative competence and information about one"s own and other cultures. It is indisputable that gaining knowledge of conventions - which may include custom and belief systems as well as systems of meaning - is also an integral part of foreign language 
learning. Especially in the era of globalization, there is an increasing demand for intercultural communication competence, to enable people to interact well with each other irrespective of cultural and social differences. Proficiency in a foreign language also enables the learner to access information and knowledge for different purposes. Since learning a foreign language implies learning about people and their cultures, language teaching and learning can be considered one way of acquiring valuable, transferable skills and knowledge that can be used in creating knowledge networks.

The increasing demand for language services and practical skills, especially among students who learn a foreign language for a specific purpose, also seems to rest on the familiar correlation between supply and demand and the relevance of the language courses offered. The lower the cost for language courses, the greater the number of students who are likely to make use of language services. However, should the cost of tuition increase, it is likely that fewer language students would be able to afford the language courses being offered. In other words, students might base their choice of which language to study on economic reasons such as cost of tuition, rather than on personal needs. It is, therefore, possible that the foreign languages currently offered at Makerere University may not necessarily be the languages that students need in the job market, and that students end up just studying any language being offered and not necessarily the one they consider relevant to their individual needs. Alongside the economic factors that may be involved in the choice of a foreign language, learning a foreign language also involves the attitudes, behavior and different expectations of language students. A positive attitude and the self-motivation to learn a foreign language may thus not necessarily conform to the rational economic behaviour that is usually associated with nonlanguage resources. Findings of the current study regarding this issue will be discussed in more detail in Section 4.1.

\subsection{Problems regarding the promotion of foreign languages at Makerere University}

At Makerere"s Institute of Languages the cost of running a foreign language course in French, German or Arabic is much higher than the cost of running an English course. Affordable teaching materials for English are readily available in Uganda while those for foreign languages like French, German and Arabic are relatively scarce. This can be explained by the fact that English is the official language of the country and therefore has a higher functional status in Uganda than Arabic, French or German.

While some students of French and German at the Institute of Languages view foreign languages as symbols of power and a means of accessing good and secure jobs in a skillsoriented market, other students simply consider foreign languages as an imposed subject which they must learn to pass examinations. However, Bourdieu (1990) emphasises the importance of language, not as an autonomous construct, but as a system determined by various socio-political processes. According to him, a language exists as a "linguistic habitus" (Bourdieu 1990:52). By this he refers to language as a set of practices that imply not only a particular system of words and grammatical rules, but also an often forgotten or hidden struggle over the symbolic power of a particular way of communicating, as well as particular systems of classification, address and reference forms, specialised lexicons and metaphors for politics, medicine and ethics (Bourdieu, cited in Duranti 1997:31).

Being able to speak a foreign language in addition to English, remains a sign of prestige in Uganda. English is predominantly used as a medium of communication, especially in urban 
homes, schools and churches. In rural areas, people mainly use local languages to communicate with each other. English, with its many varieties, remains a tool of influence and power in many domains in Uganda, while foreign languages remain languages learnt for specific purposes or because of the anticipated added advantage in the academia and business.

In the context of globalisation and taking into consideration the challenges of multilingualism, the role and function of foreign language promotion in the context of Uganda continues to be crucial. The divergent views in relation to foreign languages and their functions are generally reflected in the various approaches to the study of foreign languages among teachers. On the one hand, language learning is considered to be principally instrumental. In other words, language is learnt as a skill to use for communicating thought and information. On the other hand, language is understood to be an essential element of the thought processes of human beings, their perceptions, attitudes, self-expressions and world view. According to Sapir (1921), language is a particular "how" of thought. Sapir adds that language and our thought patterns are inextricably interrelated and are, in a sense, one and the same. While we use a foreign language to communicate our needs and concerns to others, language simultaneously reveals what and who we are to others and to ourselves.

Institutional missions and approaches to foreign language teaching and learning are a reflection of either the instrumentalist or the constitutive view of language, as discussed above. The Institute of Languages at Makerere University tends to embrace an instrumentalist focus which aims to support the needs of the foreign language learner. However, at the same time, efforts are made to emphasise the constitutive aspect of language and its relation to cultural and literacy traditions, cognitive structures, and historical knowledge.

\subsection{The case of German for Secretarial Studies at Makerere University}

According to the Makerere University Faculty of Arts Handbook (2001:123), the Bachelor of Secretarial Studies Programme was started in 1997 to meet the demands of managerial, administrative and secretarial personnel in public offices. On completion of the course, graduates should be equipped with concepts, methods, techniques and tools that allow them to contribute towards the competitiveness of government ministries, international organisations and the private sector. The course structure and content is based on the need to produce highly trained, skills-oriented graduates as set out in the Uganda Education Review Report (Kajubi 1989) and Government White Paper (1992). The course first focuses on enabling students to enhance their practical skills and widen their intellectual scope to cope with the demands of the public office. It also focuses on enabling students to acquire efficient communication skills needed in all aspects of life. Although there is theoretically an emphasis on the production of bilingual or multilingual individuals who can provide translation and interpretation services in the workplace, the circumstances under which foreign languages are currently taught make it practically impossible to produce bilingual secretaries.

When the Bachelor of Secretarial Studies programme was first introduced, students were given the opportunity to select a language to study. Three languages, namely, French, German and Swahili, were offered and the students were free to choose a language they liked. The change in policy regarding the choice of foreign language came about as a result of financial constraints faced by the Faculty of Arts in 2003. As a way of solving the problem, the Institute adopted the policy of offering only one language in each given academic year, i.e. alternating the three languages, thus marking the beginning of the imposition of offering only 
one foreign language to students of Secretarial Studies in a given academic year. The consequence of this policy is that all students admitted to the programme had to learn the foreign language being offered that particular year, which was not necessarily their language of choice.

The content of the first part of the Secretarial Studies Programme presupposes that the language learning policy, language learning environment and accessible facilities are sufficient in enabling students to enhance their practical skills and acquire efficient communication skills. These skills are crucial in order for students to be considered, after completion of the programme, as highly trained and employable graduates. The goal of the current study is to determine whether the circumstances under which foreign languages like German are currently taught and managed at Makerere University, are in fact sufficient to achieve the goals of the programme.

\section{Methodology}

\subsection{Participants}

The current study was carried out among third year secretarial students at Makerere University. Out of the 67 students who were registered for German in their first year in 2005, 54 students completed the course; these students participated in the current study. The students were adult learners above the age of 20 and from different sociocultural backgrounds. They had all started learning German at university level, i.e. they were all learning German at beginner level. They were admitted to the university by either direct entry (from secondary schools, i.e. senior six) or through the Mature Age Scheme which aims at enabling people who are already employed to upgrade their skills and qualifications at University level.

\subsection{Procedure}

The data used in the study were collected by means of a questionnaire which consisted of six sections: (1) demographic background of the participants, (2) their favourite subject, (3) relevance of learning German, (4) challenges encountered in learning foreign languages, (5) learning strategies used and (6) suggestions on how to improve the teaching and learning of German. Since the researcher is an academic member of staff at the Institute of Languages, Makerere University, and one of the lecturers for German to students of Secretarial Studies, the purpose of the study was clearly explained to the students who participated in the study. Copies of the questionnaire were distributed to students and the confidentiality of the given information was assured. The students were given two weeks within which to return the questionnaires. All questionnaires were returned. The evaluation of the Secretarial Studies programme focused on the challenges and views of these particular foreign language students who were about to graduate from Makerere University. The students were asked to mention their favorite subject, consider whether learning German was relevant to their career, specify the kind of challenges they encountered in learning German, distinguish between institutional and personal challenges, outline strategies they applied to overcome the challenges, to indicate how and whether they were motivated to learn the language, to mention factors that influenced their performance in the German language class and to suggest recommendations on how to improve the teaching of German. 


\subsection{Analysis}

The data collected were analysed according to emerging themes and sub-themes and then coded according to the percentages and inferences drawn from the data. Finally conclusions were drawn as to recommendations on the course of action for foreign language teachers, Makerere University administrators, language policy makers as well as curriculum designers.

\section{Results and Discussion}

The results of the study are presented and discussed following the order of the categories in the questionnaire, as outlined in Section 3.2. The discussion then looks at the challenges of teaching German as a foreign language, focusing on barriers to foreign language learning at Makerere University and current language learning policies at this university, as well as trends in the Ugandan language industry.

\subsection{Results}

\subsubsection{Favorite Subject}

The responses indicated that the favourite subject of Secretarial Studies students was Shorthand and Typing (15\%), followed by Principles of Ethics (13\%) and Psychology (11\%). Among the three favorite subjects, no foreign language subject was mentioned. Swahili (1\%) was the only language which was mentioned as a favourite by the students who participated in the study.

\subsubsection{Relevance of learning German as a foreign language}

The results of the study show that $67 \%$ of the students agreed that, in principle, learning German as a foreign language is relevant. They were of the view that German would help to increase their chances of employment and that it would help them to compete favorably for either international jobs or jobs at international firms with branches in Uganda and the East African region. Learning a foreign language would also enable them to meet and interact more easily with people working and living in German-speaking communities. In general, learning a foreign language was seen as a vital investment for professional courses such as Secretarial Studies.

However, the respondents who acknowledged the relevance of German as a foreign language also expressed their disappointment at not being able, upon admission, to choose the foreign language they wanted to learn. They argued that German was an imposed subject and not one that they had chosen. The respondents who considered German to be irrelevant (33\%) thought that the language was difficult to learn and reported seeing no future for the German language in the circumstances under which they would work and use the language at the workplace after completion of their degree programme. They considered learning German for three years a waste of time and resources. It is clear that for these students, having a subject imposed on them had a very negative effect on their attitude towards the subject and their motivation to learn the subject.

\subsubsection{Challenges identified in learning German as a foreign language}

The German language class that took part in this study, consisted of 54 students who had three contact hours every week. Of these participants, 26\% indicated that the biggest challenge was the pronunciation of German words and the very long German words and sentences, followed by the few hours of German every week. The absence of affordable and accessible learning materials (apart from the handouts the teachers distributed) and the 
teaching methods and approaches currently used were considered to be inappropriate by $22.2 \%$ of the respondents. The frontal method of teaching was particularly criticised because it did not enable the active participation of students, especially those who considered themselves to be learning German as an imposed subject. The frontal method of teaching refers to the teaching method whereby a teacher tends to station him/herself only in front of the classroom. The consequence is that the teacher does not move around the classroom to attend to students who may have individual problems in the course of a lesson in the classroom. This teaching method influenced the learning environment negatively and caused a lack of morale among the students. Speaking, writing, reading and listening were all considered to be challenges in the German language classes as a result of the few contact hours (three hours per week).

Responses indicated that the subject of German seems to be hard for the majority of students because of problems regarding pronunciation. The learning of grammar also constituted a problem for some respondents $(14 \%)$. The respondents felt that the teaching methods needed to be more varied to motivate students, for example, through the use of multimedia facilities, currently lacking in the foreign language classes at Makerere University. A remaining question which needs to be addressed by future research is how motivated foreign language teachers themselves are in the circumstances under which they teach and work, as this is likely to impact further on the learning experience of students.

The responses related to administrative and institutional issues indicated that $25 \%$ of the respondents considered being forced to learn a language in which they have little or no interest, as the biggest challenge. This was not only a problem for the students, but for the lecturers as well. This problem was manifested in the attitudes that students exhibited in the language classes, as signaled by absenteeism from class and non-participation in group work, in class as well as in voluntary extra language learning activities within the framework of the Makerere University German Club. As mentioned earlier, the time allocated to the teaching and learning of German is completely insufficient given the language skills that Secretarial Studies graduates are expected to have acquired upon completion of the three-year course. Finally, $14 \%$ of the respondents were satisfied with the way assessments were made in the language class.

\subsubsection{Learning strategies used by students}

The results of the study indicated that those students who were interested in learning and using German in their future careers (67\%) wanted more materials to be provided in the libraries and book banks. The learning strategy used by these motivated students was to listen to and speak the language much more in their own group discussions outside the regular classes. Another learning strategy was to take extra German language classes outside Makerere University, in addition to using self-teaching materials and buying their own learning materials. They also added that they often went to class ahead of time for consultations with and advice from the lecturer. Furthermore, they said that they had changed their attitude towards the learning of German and they tried to speak and write the little German they knew whenever they had the opportunity.

\subsubsection{Classroom composition and performance}

Responses indicated that the bigger the class, the less interaction there was between the students and the lecturers. The size of the language class seems to have a negative impact on 
the performance of especially those students who considered German to be an imposed subject. Among the students who considered themselves to be interested in learning German, $51.8 \%$ rated themselves as good in reading, $31.4 \%$ in writing, $24.1 \%$ in speaking and $33.3 \%$ in participation. As mentioned in Section 4.1.3, certain challenges such as relatively hard words, long sentences and complex grammar, large classes and few contact hours were considered by respondents as barriers to mastering the above communication skills. Among the less motivated students who considered learning German to be irrelevant (33\%), the overall self-ranking in performance was poor. This is most probably related to these students" negative attitude towards learning German as a foreign language, compounded by a lack of interest in a subject they felt they had been forced to learn.

\subsubsection{Recommendations on how the teaching of German can be improved}

Although $67 \%$ of the respondents considered learning German as a foreign language as relevant, analysis of the responses indicates that the main reason students were not interested in learning the language was because of the way they were selected to learn the language. This issue warrants serious attention, as should be clear from the discussions above. Ideally, the choice of which foreign language to learn should, especially at beginner level, be a personal decision rather than the result of a policy such as the one currently followed at Makerere University. Respondents in the current study made the following recommendations for motivating those students interested in learning German as a foreign language:

(i) Students should be given a chance to choose a foreign language they want to learn.

(ii) Language classes should be small, especially at beginner level, to enable the students to participate more in their learning.

(iii) Learning materials should be provided and the teaching approaches improved upon. These approaches should enable language students to speak much more than was the case when the study was conducted.

(iv) The current language learning policy should be revised so as to enable students, especially at beginner level, to choose a language they want to learn.

\subsection{Challenges of teaching German as a foreign language}

The issue of language teaching is as vital as it is complex, whether the concerns are about the everyday lives of people or social change, education, development, inclusion, exclusion and empowerment. The complexity of language teaching and language learning - whether the language is foreign or indigenous - is best demonstrated by its inextricable links with a society"s cultural, economic, and political life. Languages inevitably have various historical embodiments. This means that any inquiry in connection with foreign language teaching or foreign language learning in the Ugandan context, takes us not only to the role the foreign language(s) in question used to play in the past, but also to the inevitable definition of the new roles foreign languages like German, French and Arabic will have to play in the context of the East African region in the current era of globalisation.

In the past, the role of foreign languages in the African context has mostly been one of conquest, domination and suppression as foreign rule was facilitated by foreign language. Except in a handful of cases, such as Swahili in Tanzania, most colonies were run in colonial languages. Language at that time performed, and still performs, different functions as a means of communication, expression and conceptualisation. Language can be used as a means of domination, discrimination, exclusion, inclusion and as a tool of political and economic 
empowerment. Language can also be used as a powerful instrument of development in the creation of functional and sustainable knowledge networks. It is these last two aspects that accentuate the relevance of foreign language learning and teaching in Uganda today. The challenge is to sensitise students of foreign languages to understand and appreciate the added advantage of being proficient in a foreign language like French, German or Arabic, alongside Swahili which serves as the lingua franca in the region and is also the regional language of integration within the context of the East African Community.

Foreign languages are used in international contexts in the areas of business, diplomacy, media and scholarship. Knowledge of a foreign language can be an asset, while the inability to speak foreign languages may be costly, for example, when countries or communities lack mediators who are proficient in foreign languages. This is especially true in a multilingual setting since access to information on business, education, science and technology is rendered impossible without acquiring foreign languages. Foreign language learning and teaching is a dynamic industry which produces a wide range of products such as language learning multimedia accessories, language learning materials, radio and TV educational and entertainment programmes in the form of talk shows, films, documentaries and documentations.

Given the well-known fact that the foreign language industry employs many people worldwide, it is surprising that foreign language teaching at Makerere University is not given more publicity in order for prospective students to better appreciate the relevance of foreign languages in the workplace. Even though a foreign language would enable those who learn the language to have wider access to knowledge and information, thereby motivating students to invest energy, time and money in foreign language education, the degree of relevance of foreign languages beyond the language classroom in Uganda still constitutes a major challenge. The motivation of foreign language students is influenced by the value they attach to a particular language and their overall expectation of how useful it will be to them after the completion of university training.

\subsection{Barriers to foreign language learning at Makerere University}

One of the major barriers to foreign language learning at Makerere University is the decrease in the number of students for most of the courses offered at the Institute of Languages. It is possible that some of the offered courses are perceived as being outdated and therefore not relevant to the needs of language students. The patterns observed for German in the current study - specifically students" attitudes towards learning German - are generally similar to the attitudes of students towards learning French and Arabic as well.

A second barrier is the attitudes of students towards the learning of a particular language, which impacts on their mode of participation and level of performance in the language class. The criterion for the selection of students upon admission is dependent upon the performance of students at A-level and their subject combinations. As the marks in the registration forms of students clearly indicate, students that are assigned to language courses, especially at beginner level, are usually students whose grades were lower than those of students who study medicine or technology.

The changing demands for language services in the Ugandan job market constitute a third challenge. A fourth barrier which adds to the challenges in teaching foreign languages, is the 
lack of a skills-oriented and evidence-based approach to foreign language teaching, and is compounded by inappropriate teaching materials and approaches for specific language components. Also, the teaching of listening skills is not being optimally utilised. Teachers still use the traditional ways of language teaching, e.g., the grammar-translation method, which emphasises the teaching of the second or foreign language grammar and uses translation as the primary technique. Language teachers tend to teach German in English instead of using the target language as a medium of instruction so as to enable students to communicate in the language they are learning. As the findings of this study indicate, practical activities in which real-life situations are depicted, are generally not undertaken in class. This implies that the emphasis is only put on the form of the language being taught and not on enabling and empowering students to express themselves in the target language. Thus, there seems to be a discrepancy between what the curricula prescribe and what the job market demands. The curricula prescribe the teaching of linguistic knowledge while the job market demands practical skills. The challenge is to provide students with the foundational linguistic knowledge they need, while also equipping them with practical skills and learning strategies to enable them to be in charge of their own learning beyond the foreign language class.

The fact that, at present, there are no self-evaluation mechanisms for either the language students or the language teachers constitutes a fifth barrier. There is a clear lack of institutionalized tools and mechanisms in place to evaluate and assess the teaching styles and learning styles as well as the performance of foreign language students on a regular basis. Besides university examinations, prescribed tests and continuous assessments which are obligatory for all university courses, there are also no other specific institutionalised tools, such as language placement tests, which assess the competences of language students before they are admitted to language programmes. Language placement tests are especially useful with students at beginner level. There is also no regular evaluation of specific language programmes after students complete language courses. The curriculum in the Ugandan education system is predominantly examination-oriented and this is evident at all examinable levels of education.

A final, sixth barrier is the absence of a common framework of reference for languages, which would provide guidelines and standards to facilitate educational and occupational mobility, as is the case with the Common European Framework of Reference for Languages (CEFR). This document was compiled by the Council of Europe as the main part of the project "Language Learning for European Citizenship" (Council of Europe 2001). It serves as a practical tool by providing clear standards for goals to be attained at successive stages of language learning and for evaluating outcomes in an internationally comparable manner. The CEFR is used as a guideline to describe achievements of foreign language students across Europe and, increasingly, in other countries; it also serves as a framework for language learning, teaching and assessment. The CEFR divides students into the following three broad divisions which can be divided further, yielding six reference levels: (i) A (A1 and A2), known as Basic Speaker, (ii) B (B1 and B2), namely Independent Speaker and (iii) C (C1 and C2), referred to as Proficient Speaker. The CEFR describes what a learner is supposed to be able to do in reading, listening, speaking and writing at each level, thereby identifying and describing the competences a language learner should attempt to acquire. It also proposes a framework for assessment in the form of a number of levels defined in terms of linguistic and socio-cultural competence (Byram 1997). Uganda as well as the East African region should take a leaf from the CEFR, so that foreign language students are equipped with competences and skills that 
can enable them to work not only in the budding Ugandan language industry but also anywhere else in the region.

\subsection{Language learning policies}

At Makerere University, the current policy for the Institute of Languages does not include a needs analysis. Such an analysis would typically be undertaken to assess the language needs of various foreign language students before they are selected for a degree course for which the learning of a foreign language is a vital course component. Furthermore, no language placement tests are administered to assess the proficiencies of students before they are selected for the available language programmes. The consequence of this problematic language learning policy is the enrolment of language students who have negative attitudes towards the language they are supposed to learn, as indicated by the findings presented in Section 4.1.

Naturally, the language learning environment in which foreign languages are presently taught at university level have an impact on the academic performance and language proficiency of the students. This is supported by the responses of participants in the present study. The unavailability of teaching materials is an additional factor that influences the teaching of foreign languages. Textbooks that are contextually relevant, easily available and affordable are important resources in the Ugandan language industry. If the content of textbooks is relevant to the experiences of language students and addresses issues related to their culture(s) and multilingual environment, these teaching materials are likely to stimulate the interest of foreign language students. There is a need to design teaching materials tailored towards the needs of the language industry in Uganda.

\section{Trends in the Ugandan language industry}

The language industry in Uganda currently encompasses all aspects of training in written and spoken language. Language services include training in writing skills, translation services and language training. The language industry in Uganda is undergoing changes in terms of what the curricula and the skills-oriented job market demand. In addition to a growing diversity within the corporate and consumer structures and growing demands for language services, there are still certain challenges as well as opportunities. These will now be discussed in more detail.

\subsection{Lack of visibility}

Although there is an increase in demand for language services, especially in the media, the activities in the language industries in Uganda are still largely unrecognised. The reduced visibility of the advantages of learning foreign languages in the eyes of the Ugandan public in general explains why especially young people who learn languages at school and at university level tend to question the relevance of the foreign languages they learn. It seems that they are largely unaware of the employment prospects for people who specialise in foreign languages. Although the language industry in Uganda is crucial to tourism, communication skills, advertising, interpretation and translation, vague policies and the absence of dedicated professional associations and networks also contribute to the lack of awareness of the potential for foreign languages in the language industry in Uganda. 


\subsection{Absence of local language networks}

Although there are a few language centres in and around Kampala, the capital of Uganda, there is currently no umbrella organisation which streamlines and guides the activities undertaken by language teachers. There is, for example, no translators" guild, which should be charged with the responsibility of registering and certifying translators in Uganda. The language centres in Kampala at the moment include the Goethe Zentrum Kampala (GZK) which works together with Alliance Française (AF) under the same roof, Kampala Language Centre, DIFRA Language Services, LUBA Language Consults and St Augustine Language Resource Centre. The above centres tend to run their language programmes independently as business-oriented organisations and not under an umbrella network. Although there are teachers" associations for teachers of French and German, there is to date no network for foreign language researchers in Uganda. Language networks would play a vital role as a catalyst in the development of the language industry in Uganda and would provide language teachers with structures, mechanisms and tools that would help the language industry in Uganda standardise language programmes and take responsibility for their growth in the local context.

\subsection{Opportunities in the Ugandan Language Industry}

The opportunities inherent in the teaching of foreign languages in Uganda are manifested in the teaching of language for various specific purposes, such as language of diplomacy and of business, language for tourism and travel management, and health communication. An emphasis on evidence-based teaching would enable language teachers to standardise procedures, which would make it possible to assess students" needs before language courses are developed. Evaluations of language courses on a regular basis would also offer an opportunity for language teachers in Uganda to better plan and market language courses, as well as to improve on their foreign language teaching approaches.

\subsection{Practical applications of findings}

This paper focused on the challenges and opportunities with regard to foreign language education in Uganda; as such, it has implications for the application of that which is taught or learnt in real-life situations. The findings of the study reported here offer useful insights for curriculum developers, administrators, decision and policy makers as well as foreign language teachers. As the research depicts both challenges and opportunities of foreign language teaching and learning at Makerere University, it is important for all stakeholders to make use of this knowledge.

It is also important to sensitise the university administrators and decision makers, as well as language students, to the relevance of foreign languages and the role foreign languages play in the job market at regional, national and international levels. If foreign language teaching is to be promoted at Makerere University and in the rest of Uganda, there should be a shift from traditional and purely theoretical ways of language teaching to practical and communicative ways of language teaching. This will not only attract more students but will also enable students to develop the communicative competence required to be involved in their own learning. These are some of the qualities employers look for in, and expect from, university graduates in this era of globalisation.

If the learning and teaching of foreign languages is to play a meaningful role in higher education in the Ugandan context, and if language courses are to thrive autonomously, a 
transformation of language programmes and structures must be undertaken. This idea also presupposes a transformation which should take place in the language industry in Uganda, a creation of networks which can enhance an exchange and sharing of ideas and expertise among foreign language teachers and a deliberate attempt to cross disciplinary boundaries. This approach would enable the incorporation of diverse materials in language courses in order to promote a wide cultural understanding through research and teaching.

Foreign language programmes at Makerere University should be structured to produce language users and thinkers who can demonstrate interlingual and intercultural competence in the respective areas where they operate. It is indisputable that language training often seeks to replicate the competence of an educated native speaker. However, the Ugandan foreign language user may not optimally reach this goal. The goal of enabling foreign language students to acquire intercultural competence should place value on the ability of such students to operate between languages and to mediate between cultures. The aim should be to train and educate foreign language students to function as informed and knowledgeable mediators with speakers in the target languages and to reflect on the world and themselves through the lens of a foreign language and a foreign culture. This approach to foreign language teaching would enable foreign language students to appreciate the differences between their own and other languages, cultures and worldviews.

\section{Conclusion}

In the course of acquiring functional language abilities, foreign language users in Uganda would be in a position to focus on areas which foreign languages at Makerere University have in common. The goal will be to achieve the following: enable students to acquire critical language awareness, interpretation and translation skills, historical and political consciousness, social sensibility, a basic knowledge of the history and geography of Uganda and the country whose language is being learnt as a foreign language. This will also enable students to acquire knowledge about the culture and literature of the society whose language students are learning, enhancing the ability to understand and process information from radio, television and print media, and enhancing the capacity and skills to undertake research in the language being learnt. The suggested curricular reform would situate foreign language learning and teaching within an appropriate cultural, historical and cross-cultural frame and thereby boost the foreign language industry in Uganda. The adaptation of functional teaching approaches will enable diverse language students to acquire employability skills and perform functions relevant to their chosen areas of specialisation.

It is well known that the understanding of the unknown from the perspective of foreign language students is also influenced by their expectations, motivation, learning environment and the value they attach to the foreign language being learnt. Foreign languages should therefore be taught in a way that enables students to express themselves appropriately and effectively in multilingual and multicultural contexts upon the completion of a language course. The focus should not only be on linguistic content or on making foreign languages teachable but on the functionalising of foreign language teaching through designing foreign language courses from which the future foreign language learner can benefit. This is the position which Königs (2010) also argues for when he discusses the possibilities and limitations of study reforms from the perspective of teaching German as a foreign language in 
the European context. As language teachers, we give the most fulfillment to language students and also gain the most productivity from them, when we position them to use their strengths.

\section{References}

Bourdieu, P. 1990. The logic of Practice. Stanford University Press.

Byram, M. 1997. Teaching and Assessing Intercultural Communicative Competence. Clevedon: Multilingual Matters.

Council of Europe. 2001. Common European Framework of Reference for Languages: Learning, Teaching, Assessment. Cambridge: Cambridge University Press.

Duranti, A. 1997. Linguistic Anthropology. Cambridge: Cambridge University Press.

Kajubi, W.S. 1989. Education for National Integration and Development: Report of the Education Policy Preview Commission. Kampala, Uganda: Ministry of Education.

Königs, F.G. 2010. Zwischen Hoffen und Bangen. Möglichkeiten und Grenzen einer europäischen Studienreform am Beispiel des Faches Deutsch als Fremdsprache. Info DaF 1(37): 3-20.

Makerere University. 2001. Faculty of Arts Handbook 2001-2002. Makerere University.

Sapir, E. 1921. Language: An Introduction to the Study of Speech. London: Rupert HartDavis.

Uganda Government. 1992. Government White Paper on the Implementation of the Recommendation of the Report of Education Review Commission. Kampala. 